Research Article

\title{
Water Reservoir Multiobjective Optimal Operation Using Grey Wolf Optimizer
}

\author{
Alireza Donyaii (D), Amirpouya Sarraf $(\mathbb{D}$, and Hassan Ahmadi $(\mathbb{D}$ \\ Department of Civil Engineering, Roudehen Branch, Islamic Azad University, Roudehen, Iran \\ Correspondence should be addressed to Amirpouya Sarraf; st.ar_donyaii@riau.ac.ir
}

Received 2 September 2020; Revised 29 September 2020; Accepted 21 October 2020; Published 6 November 2020

Academic Editor: Masoud Mirtaheri

Copyright (c) 2020 Alireza Donyaii et al. This is an open access article distributed under the Creative Commons Attribution License, which permits unrestricted use, distribution, and reproduction in any medium, provided the original work is properly cited.

\begin{abstract}
This study develops the Multiobjective Grey Wolf Optimization (MOGWO) algorithm to obtain the optimum rules on the operation of the Golestan Dam in Golestan Province, Iran, under the climate change conditions. The tow objective functions defined in the optimization process include minimizing the vulnerability and maximizing the reliability indices of the model under baseline and climate change conditions periods. Results showed that the river flow would decline by 0.17 percent of the baseline period under climate change conditions in addition to increasing the temperature by $20 \%$, as well as decreasing the rainfall by $21.1 \%$. Moreover, the extent of vulnerability index variations in baseline and climate change conditions was $16-45 \%$ and $10-43 \%$, respectively. The range of reliability index variations in baseline and climate change conditions was 47-90\% and $27-93 \%$. On the other hand, the vulnerability index has also been measured at $29 \%$ and $27 \%$ for baseline and climate change conditions, respectively, with 75 percent of reliability. Comparison of the reservoir release rate and water demands for all of the Pareto points indicates a rise in release rates for climate change conditions relative to the baseline one; as the result, the higher adjustment in the reservoir release rates to its demand volumes will be highlighted as the higher dam efficiency in climate change conditions.
\end{abstract}

\section{Introduction}

Water resources systems are very complex, and in terms of water resources management and use, the advantages of water supplies can be maximized. Therefore, in order to promote sustainable growth and optimize profits, it is important to participate in management activities to satisfy customer needs, particularly in areas where the mismatch problem is severe $[1,2]$.

The operation of dam reservoirs is of great significance because of the inadequate water supplies, owing to the economic value of the reservoirs resulting from the optimum management of water resources, growing water demands, and the scarcity of usable water supply. Furthermore, it is important to use a system that provides optimum management of the operation of dam reservoirs, particularly under the conditions of climate change. Thus, both priorities and multiobjective modeling frameworks must be used to derive decision-making alternatives [3].
Therefore, a group of approximate solution algorithms called metaheuristic algorithms has been produced over the last decades in the optimization of the reservoir system that investigate the computational complexity efficiently and safely and avoid the solution method from being stuck within the boundaries of the search space. For multiobjective optimization of water resource systems, particularly dam reservoirs, several methods have been used in the recent decades. Multiobjective evolutionary algorithms are among the most significant and commonly used, providing a range of optimal solutions in each iteration that can be expressed in the form of the Pareto curve [4].

Sun et al. [5] proposed a model of multiobjective optimization for reservoir operation (MORO) with the objectives of maximizing water diversion and power generation. The multiobjective evolutionary algorithm based on decomposition with adaptive weight vector adjustment (MOEA/D-AWA) was applied to solve the MORO problem. In addition, the performance of the MOEA/D-AWA was 
compared with two other algorithms based on the hypervolume index.

Their results showed that (1) the proposed model was effective and reasonable in theory; (2) the optimization results obtained by MOEA/D-AWA demonstrated this algorithm could be applied to the MORO problem, providing a set of evenly distributed nondominated solutions; and (3) water diversion and power generation were indeed contradictory objectives.

Donyaii et al. [6] introduced a combined model of Crow Search (CSA) and Grey Wolf (GWO) Optimization algorithms called Grey Wolf -Crow Search Hybrid algorithm to optimize the operation of the single-reservoir system of the Golestan Dam, considering the objective function (supplying downstream water demand). To compare the convergence and performance of these algorithms, the statistical parameters of each algorithm were calculated and compared with each other, as well as with the analytical solution of a nonlinear programming model (i.e., GAMS Software). Then, in order to analyze the performance of the algorithms, the Combinative Distance-based Assessment (CODAS) Multicriteria DecisionMaking Model was used to rank the decision alternatives (i.e., optimization algorithms) based on volumetric and time-based reliability, reversibility, and vulnerability criteria, as well as the optimized objective function. Their results showed that not only the hybrid model approach has a response closer to the absolute optimal value but also the CODAS Multicriteria Decision-Making Model identified that it was better than its constituent algorithms, namely, CSA Optimization and GWO algorithm in optimizing the objective function.

$\mathrm{Wu}$ et al. [7] carried out a multiobjective hydropower reservoir activity using NSGA-II and objective functions to optimize water supply and hydropower generation benefits and mitigate water scarcity for environmental demands and demonstrated the efficacy and reliability of the proposed algorithm and model by using it in the Yellow River of China's Lango reservoir.

Ashofteh et al. [8] used the multipurpose genetic programming (GP) to optimize the Aydoghmush dam reservoir in East Azerbaijan Province in Iran under baseline and climate change conditions. The optimization results revealed that the rules of reservoir performance that are involved in climate change lead to an improvement from $29 \%$ to $32 \%$ in the reservoir performance due to climate change compared to baseline. Ehteram et al. [9] applied the kidney algorithm to generate an optimal operation of the Aydoghmush reservoir in Eastern Azerbaijan Province in Iran to decrease irrigation deficit downstream of the dam. They compared the results of the kidney algorithm with other evolutionary algorithms, including bat (BA), genetic (GA), particle swarm (PSO), shark (SA), and weed algorithms (WA). The results showed that the kidney algorithm provided the best performance against the other evolutionary algorithms.

The efficiency of two models of Extreme Learning Machines (ELM), Artificial Neural Network (ANN), and the combination of two models with wavelet propagation algorithms (W-ELM and W-ANN) was evaluated by Afkhamifar \& Sarraf [10]. They discovered the W-ELM-QPSO hybrid model has increased quality than other models and this model has a high speed in terms of training and testing speed in addition to forecasting power than other models.

In the present study, as an innovative approach in the field of water management, the development and implementation of the multiobjective Grey Wolf optimization algorithm (MOGWO) was proposed, which was not discussed in the previous studies.

Moreover, the optimal operation rules of the Golestan Dam reservoir (in Golestan Province, Iran) in baseline conditions (from April 2006 to October 2018) and climate change conditions (April 2021 to October 2033) using MOGWO algorithm, with two objectives of minimizing vulnerability and maximizing reliability index in demandsupply, were determined and compared in the mentioned periods as a necessity for the future water recourses planning management.

The methods applied in this research are as follows:

(i) Assessing climate change parameters

(ii) Simulation of rainfall-runoff processes for determining Golestan Dam reservoir discharge volume in Iran

(iii) Estimation of baseline water demand volume and climate change conditions and multiobjective operating rules extraction (based on three variables of storage volume, demand volume, and discharge to the reservoir) in climate change and baseline conditions

Ultimately, the procedures for this investigation were to compare optimum allocation policies in baseline and climate change conditions with the performance measures and efficiency indices of the reservoir.

\section{Initial Information and Processing}

In this study, in order to obtain a more realistic approximation, by averaging three scenarios (i.e., RCP 2.6, RCP 4.5, and RCP 8.5), a new scenario named as the average scenario was proposed after downscaling the CANESM2 Climate model with SDSM 4.2 software. The findings show that, also in the average scenario, the monthly average temperature increases in all three cases, which averages $20 \%$ for the prediction duration. Analyzing the average monthly precipitation variations have shown that the drop in the next period of precipitation rate was obvious, and this trend has been diminished by to 21.1 percent regarding to the baseline.

A second-order Neurofuzzy model with a Gaussian membership function was conducted to simulate the rainfall-runoff process focusing on the climate change phenomena at the entrance to the Golestan Dam, including 20 training epochs and 10000 iterations for $95 \%$ of training data (in each prediction). ANFIS's best influence radius for calculating the runoff reached 0.04 .

Consequently, the volume of runoff during the climate change conditions with respect to the baseline period would be decreased to 0.17 percent. Therefore, this could be a warning for water resources management. 


\section{Optimization Model Development}

The simulation of the reservoir through the continuity equation would be described as follows:

$$
\begin{aligned}
S_{(t+1)} & =S_{(t)}+Q_{(t)}-\operatorname{Re}_{(t)}-S p_{(t)}-\operatorname{Loss}_{(t)}, \\
\operatorname{Loss}_{(t)} & =A_{(t)} \times E v_{(t)}, \\
A_{(t)} & =a S_{(t)}^{3}+b S_{(t)}^{2}+c S_{(t)}+d,
\end{aligned}
$$

where $A_{(t)}$ implies to the reservoir surface in the $t$-th month, $E v_{(t)}$ is the net evaporation from the reservoir (the difference among the amount of rainfall and evaporation in the $t$-th month), and $a, b, c$, and $d$ imply the constant coefficients of the volume-area equation of the reservoir for the Golestan Dam reservoir. $Q_{(t)}$ is the inflow to the reservoir in the $t$-th month, $\operatorname{Re}_{(t)}$ is the release from the reservoir in the $t$-th month, $S p_{(t)}$ is the reservoir overflow in the $t$-th month, $\operatorname{Loss}_{(t)} s$ the evaporation losses in the $t$-th month, and shortage is the difference between the demand and the actual release when it is less than the demand. Overflow of the reservoir imposes some constraints on the calculations as follows:

$$
S_{P_{t}}= \begin{cases}S_{t}+Q_{t}-\operatorname{Re}_{t}-\operatorname{Loss}_{(t)}-S_{\max }, & \text { if } S_{t}+Q_{t}-\operatorname{Re}_{t}-\operatorname{Loss}_{(t)}>S_{\max }, \\ 0, & \text { if } S_{t}+Q_{t}-\operatorname{Re}_{t} \leq S_{\max } .\end{cases}
$$

Other constraints are as follows:

$$
\begin{gathered}
S_{\min } \leq S_{t} \leq S_{\max }, \\
\mathrm{Re}_{\min } \leq \mathrm{Re}_{t} \leq \mathrm{Re}_{\max },
\end{gathered}
$$

where $S_{\max }$ and $S_{\min }$ imply the maximum and minimum volumes of the reservoir and $\mathrm{Re}_{\max }$ and $\mathrm{Re}_{\min }$ are referred to as the maximum and minimum releasable volumes from the reservoir, respectively [11].

Two objective functions have been used in the present study to mitigate vulnerability and optimize the reliability index in baseline and climate change conditions based on the following equations [12]:

Minimize $F_{1}=\frac{\sum_{t=1}^{T}\left(D_{t}-\mathrm{Re}_{t} \mid \mathrm{Re}_{t}<D_{t}\right)}{\left[N_{t=1}^{T}\left(\mathrm{Re}_{t}<D_{t}\right)\right] \cdot D_{\mathrm{Max}}}, \quad \forall_{t}=1,2, \ldots, T$,

Maximize $F_{2}=\frac{N_{t=1}^{T}\left(D_{t}-\mathrm{Re}_{t} \mid \operatorname{Re}_{t} \geq D_{t}\right)}{T}, \quad \forall_{t}=1,2, \ldots, T$,

where $F_{1}$ implies the objective function of a vulnerability index, $F_{2}$ is the objective function of the reliability index, $D_{t}$ is referred to as the demand volume throughout the $t$-th period, $D_{\mathrm{Max}}$ implies the maximum water demand in the operating period, $N_{t=1}^{T}\left(\operatorname{Re}_{t}<D_{t}\right)$ implies the number of months of water shortage, and $N_{t=1}^{T}\left(D_{t}-\mathrm{Re}_{t} \mid \mathrm{Re}_{t} \geq D_{t}\right)$ implies the number of months of water supply equations:

$$
\begin{gathered}
S_{t} \geq S_{\min }, \quad \forall_{t}=1,2, \ldots, T, \\
\operatorname{Re}_{t} \leq \operatorname{Re}_{\max }, \quad \forall_{t}=1,2, \ldots, T .
\end{gathered}
$$

In the event of violations of constraints 9 and 10, penalty functions will be introduced to the objective functions as follows:

$$
\begin{aligned}
F_{1}\left(\text { or } F_{2}\right) & =F_{2}\left(\text { or } F_{1}\right) \pm\left[A^{\prime} \cdot\left(\frac{S_{\min }-S_{t}}{S_{\max }-S_{\min }}\right)+B^{\prime}\right], \\
\forall_{t} & =1,2, \ldots, T, \\
F_{1}\left(\text { or } F_{2}\right) & =F_{2}\left(\text { or } F_{1}\right) \pm\left[C^{\prime} \cdot\left(\frac{\operatorname{Re}_{t}}{D_{\mathrm{Max}}}\right)+D^{\prime}\right] \\
\forall_{t} & =1,2, \ldots, T,
\end{aligned}
$$

where $\left[A^{\prime} \cdot\left(S_{\min }-S_{t} / S_{\max }-S_{\min }\right)+B^{\prime}\right]$ implies the penalty function achieved from the violation of equation (9) and $\left[C^{\prime} \cdot\left(\mathrm{Re}_{t} / D_{\mathrm{Max}}\right)+D^{\prime}\right]$ is referred to as the penalty function resulted from the violation of equation (10). $A^{\prime}$ to $D^{\prime}$ coefficients imply the positive constants of penalty functions with $A^{\prime}=1, B^{\prime}=0.5, C^{\prime}=1$, and $D^{\prime}=16$ values [12].

3.1. Operation Rule Curve. In the existing study, the rule of decision is derived based on equations (13) and (14) for the operation of the Golestan Dam single-reservoir system to minimize the vulnerability resulted from the system shortage and to provide the necessary demand and also to optimize the demand-supply reliability using MOGWO algorithm equations:

$$
\begin{aligned}
& \mathrm{Re}_{\mathrm{bt}}=g_{1}\left(Q_{\mathrm{bt}}+S_{\mathrm{bt}}+D_{\mathrm{bt}}\right), \quad \forall_{t}=1,2, \ldots, T, \\
& \operatorname{Re}_{\mathrm{ft}}=g_{2}\left(Q_{\mathrm{ft}}+S_{\mathrm{ft}}+D_{\mathrm{ft}}\right), \quad \forall_{t}=1,2, \ldots, T,
\end{aligned}
$$

where $g_{1}\left(Q_{b t}+S_{b t}+D_{b t}\right)$ of the first option implies the rule from MOGWO in the baseline operating period for baseline conditions and $g_{2}\left(Q_{\mathrm{ft}}+S_{\mathrm{ft}}+D_{\mathrm{ft}}\right)$ of the second option implies the rule from MOGWO in the climate change operating period for climate change conditions. The $b$ index is for baseline conditions, and the $f$ index is for climate change conditions [12].

3.2. Grey Wolf Optimization. Mirjalili et al. [13] proposed the Grey Wolf Optimization Algorithm (GWO) to mimic the hunting behavior of Grey Wolves in nature. The key goal of the GWO strategy is to use a network of searching agents to determine the optimal for a specific problem. Usually, these wolves reside in groups of between five and twelve. The basic difference between the algorithm of Grey Wolf Optimization and the other algorithms of optimization is the dominant social structure that decides the convergence rate for each optimization iteration. Furthermore, the Grey Wolf Optimization algorithm mimics the wolves' foraging actions in finding and assaulting prey [13]. Figure 1 shows the 


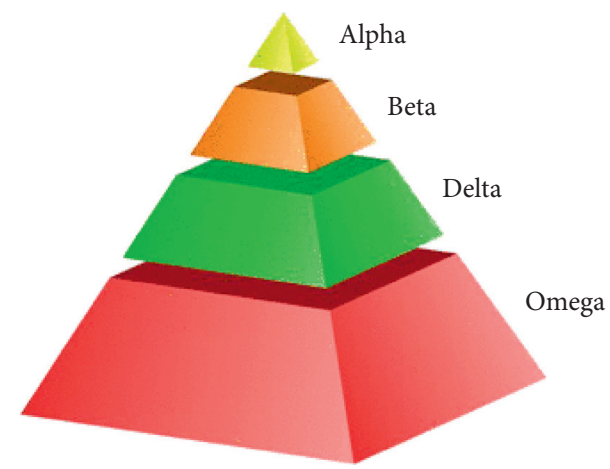

FIgURE 1: Social hierarchy of the group of Grey Wolves [13].

hierarchical order of the group of wolves. The leader is shown by alpha as the strongest alternate member. In reality, the alpha, accompanied by the other wolves, is the leader wolf. Beta is the second alternative candidate who encourages alpha in decision-making and is a conduit between the leader and the rest of the squad. The third alternate nominee responsible for providing data for two higher stages (alpha and beta) is indicated by delta. In comparison, the remaining alternatives are indicated by the omega, which is responsible for submitting information to the three higher stages. Furthermore, the hunting process consists of three steps: the prey is found, surrounded, and targeted. Therefore, the Grey Wolves Empirical hunting technique used to address a structural optimization topic is demonstrated by GWO. It is, then, presumed that the victims are the ideal solution to the issue.

The motion of the top three stages, provided in the given equations, replicates the covering of the victim by Grey wolves [13].

$$
D=\left|\vec{C} \cdot \overrightarrow{X_{p}}(t)-\vec{X}(t)\right|
$$

where in $t$ represents the current iteration, $\mathrm{Xp}$ represents the victim's location vector, $X$ indicates the Grey wolfs position, and $\mathrm{C}$ is the coefficient's vector. As stated in Figure 2, the consequence of vector $D$ is, then, used by the following equations to move the individual object to or away from the area where the best solution representing the victim is located [13]:

$$
\begin{aligned}
\vec{X}(t+1) & =\vec{X}_{p}(t)-\vec{A} \cdot \vec{D}, \\
\vec{A} & =2 \vec{a} \cdot \vec{r}_{1}-\vec{a}, \\
\vec{C} & =2 \cdot \vec{r}_{2},
\end{aligned}
$$

where $\vec{r}_{1}$ is selected randomly in $[0,1]$ and $\vec{a}$ is reduced from 2 to 0 using a fixed quantity of iterations.

In case $|A|<1 \mid$, this corresponds to the behavior of the exploitation and simulates the behavior of the attack on the prey. Otherwise, if $|A|<1$, this fits the exploration behavior and simulates the victim's wolf spacing away, as illustrated in Figure 2. The proposed values for $A$ are given in $[-2,2]$. Therefore, the following mathematical expressions are used to measure three higher levels alpha, beta, and delta [13].

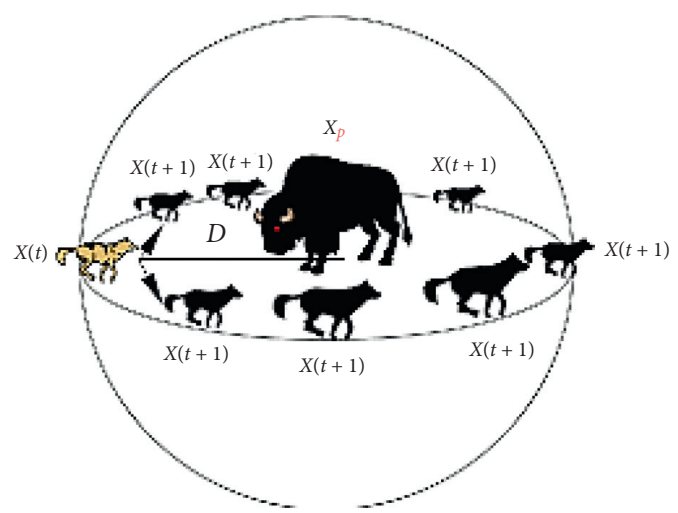

FIGURE 2: Graphical representation of Grey wolf hunting procedure in a circle or sphere space around the prey $\left(X_{p}\right)$ based on the direction $(D)$ between the wolf $\left(X_{(t)}\right)$ and the prey [13].

This refers to the exploitation action in the case $|A|<1$ and approximates the actions of the attack on the victim. Otherwise, if $|A|>1$, this matches the exploration actions and approximates the positioning of the victim's wolf, as seen in Figure 2. In $[-2,2]$, the suggested values for A are provided. The following mathematical equations are, then, used to calculate alpha, beta, and delta at three higher stages [13].

$$
\begin{aligned}
& \overrightarrow{D_{\alpha}}=\left|\overrightarrow{C_{1}} \cdot \overrightarrow{X_{\alpha}}-\vec{X}\right| \overrightarrow{X_{1}}=\overrightarrow{X_{\alpha}}-\overrightarrow{A_{1}} \cdot\left(\overrightarrow{D_{\alpha}}\right), \\
& \overrightarrow{D_{\beta}}=\left|\overrightarrow{C_{2}} \cdot \overrightarrow{X_{\beta}}-\vec{X}\right| \overrightarrow{X_{2}}=\overrightarrow{X_{\beta}}-\overrightarrow{A_{2}} \cdot\left(\overrightarrow{D_{\beta}}\right), \\
& \overrightarrow{D_{\delta}}=\left|\overrightarrow{C_{3}} \cdot \overrightarrow{X_{\delta}}-\vec{X}\right| \overrightarrow{X_{3}}=\overrightarrow{X_{\delta}}-\overrightarrow{A_{3}} \cdot\left(\overrightarrow{D_{\delta}}\right) .
\end{aligned}
$$

We consider that alpha, beta, and delta have enough knowledge of the potential location of the prey for mathematically mimicking the Grey Wolf hunting process. In reality, as defined in the following equations, the first three best solutions that have been obtained are rescued and enable the other agents to adjust their positions based on the best agents alpha, $\beta$, and $d$ [13]:

$$
\vec{X}(t+1)=\frac{\overrightarrow{X_{1}}+\overrightarrow{X_{2}}+\overrightarrow{X_{3}}}{3}
$$

\section{Results and Discussion}

Using metaheuristic algorithms in civil engineering optimization issues is inevitable $[14,15]$. In this study, the MOGWO metaheuristic algorithm was used to derive the operating rules from the Golestan Dam Single-Reservoir System in Northeastern Iran, Golestan Province (Figure 3), and a 4200-hectare downstream network. The reservoir has a capacity of 43.7 million cubic meters at the normal level, 100 meters above sea level, and 54 million cubic meters at the level of overflow.

The curve of the surface-volume of the reservoir was extracted through the following equation with the $R^{2}=0.997$ correlation coefficient and based on Figure 4:

$$
Y=-0.003 X^{2}+0.184 X+1.435 \text {. }
$$




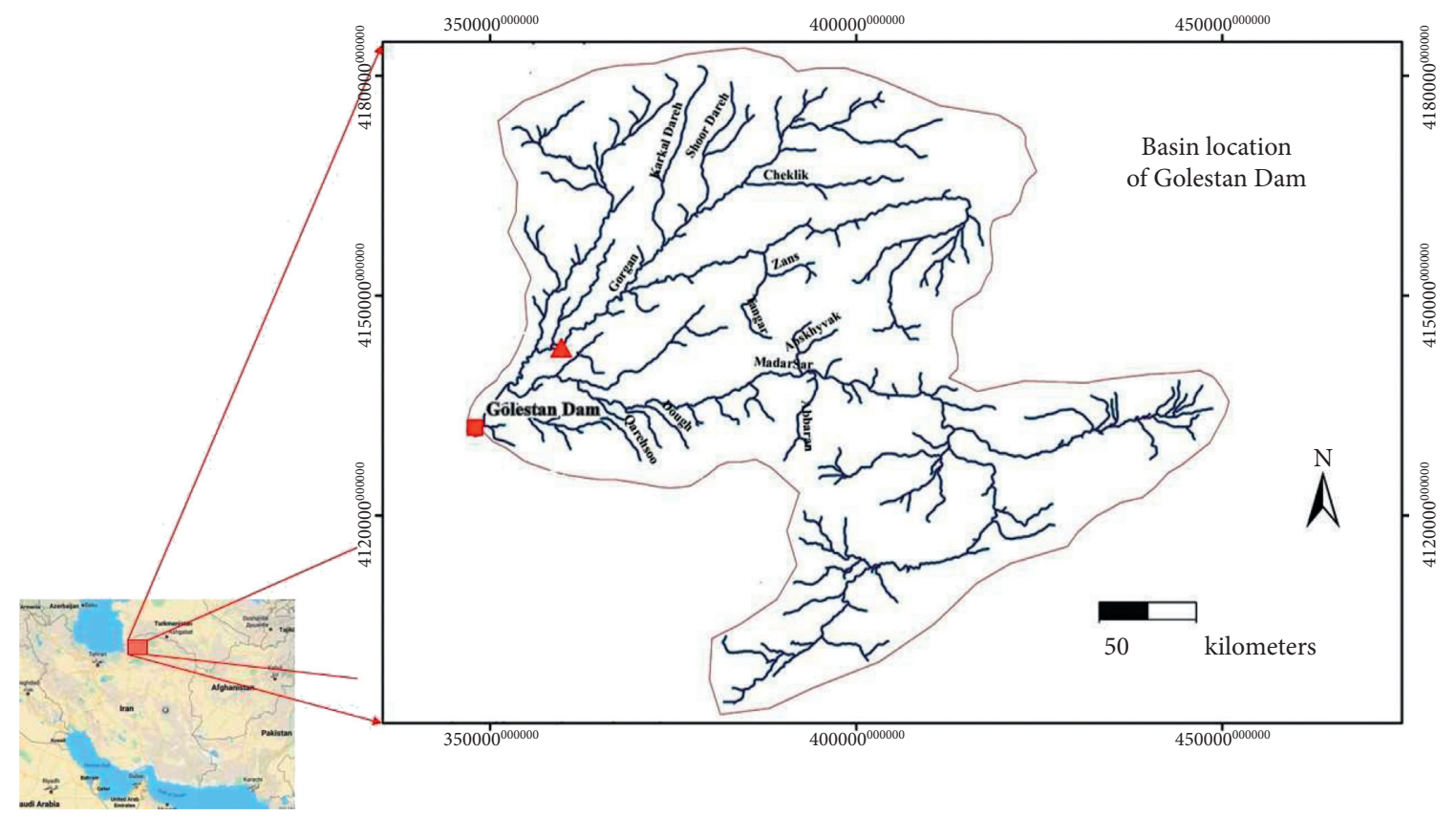

Figure 3: The geographical location of the study region.

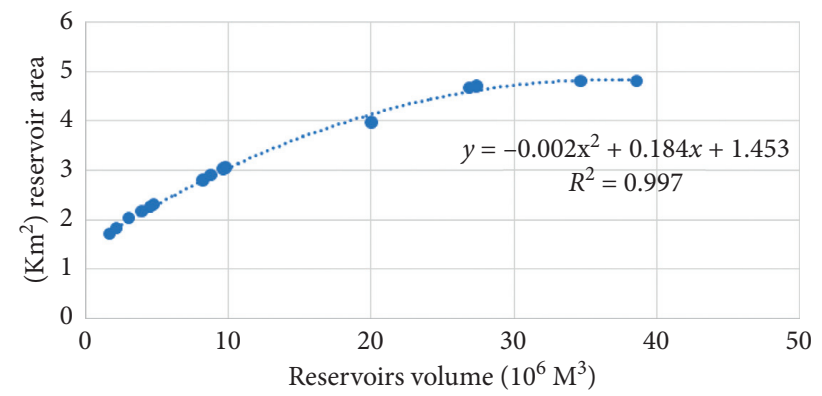

Figure 4: Surface-volume curve of the Golestan Dam reservoir.

The maximum baseline and climate change demands are 37.84 and 41.86 million cubic meters. Figure 5 indicates the average monthly release volume, as well as the monthly average evaporation volume and the monthly average demand volume for water under baseline and climate change conditions.

The results revealed that the ratio of discharge into the reservoir and demand for water under climate change conditions decreased by approximately 17 percent and increased by 10 percent relative to baseline conditions, respectively.

The optimum operating rules of the Golestan Dam reservoir were obtained from a two-targeted problem, using the MOGWO algorithm. The two-target problem involved maximizing demand reliability and reducing system vulnerability.

According to Figure 6, if we assume the model reliability index of $75 \%$, there will be an obvious difference between the vulnerability values under the climate change and baseline conditions. In other words, Figure 6 displays the effects of the two-objective optimization algorithm in the sense of the Pareto curve for baseline and climate change conditions. There are 16 percent to 45 percent and 10 percent to 43 percent of vulnerability shifts in baseline and climate change conditions as stated in Figure 6. In baseline and climate change conditions, the number of reliability adjustments is 47 percent to 90 percent and 27 percent to 93 percent. In comparison, for baseline conditions and climate change conditions, 29 percent and 27 percent of vulnerabilities are generated for every 75 percent of reliability, respectively. In other words, the degree of vulnerability and reliability of climate change is higher than that of the average. A reservoir activity rule, including its vulnerability and reliability indices, is shown by each point in the Pareto curve (Figure 6). None of the Pareto points has taken precedence over others; based on catchment conditions and policies, they can differ. The next phase was to determine the optimum level of rules on water demand in the sense of baseline and climate change conditions. Therefore, the optimum rules were compared to the optimum rules arising from climate change conditions. On the other hand, 


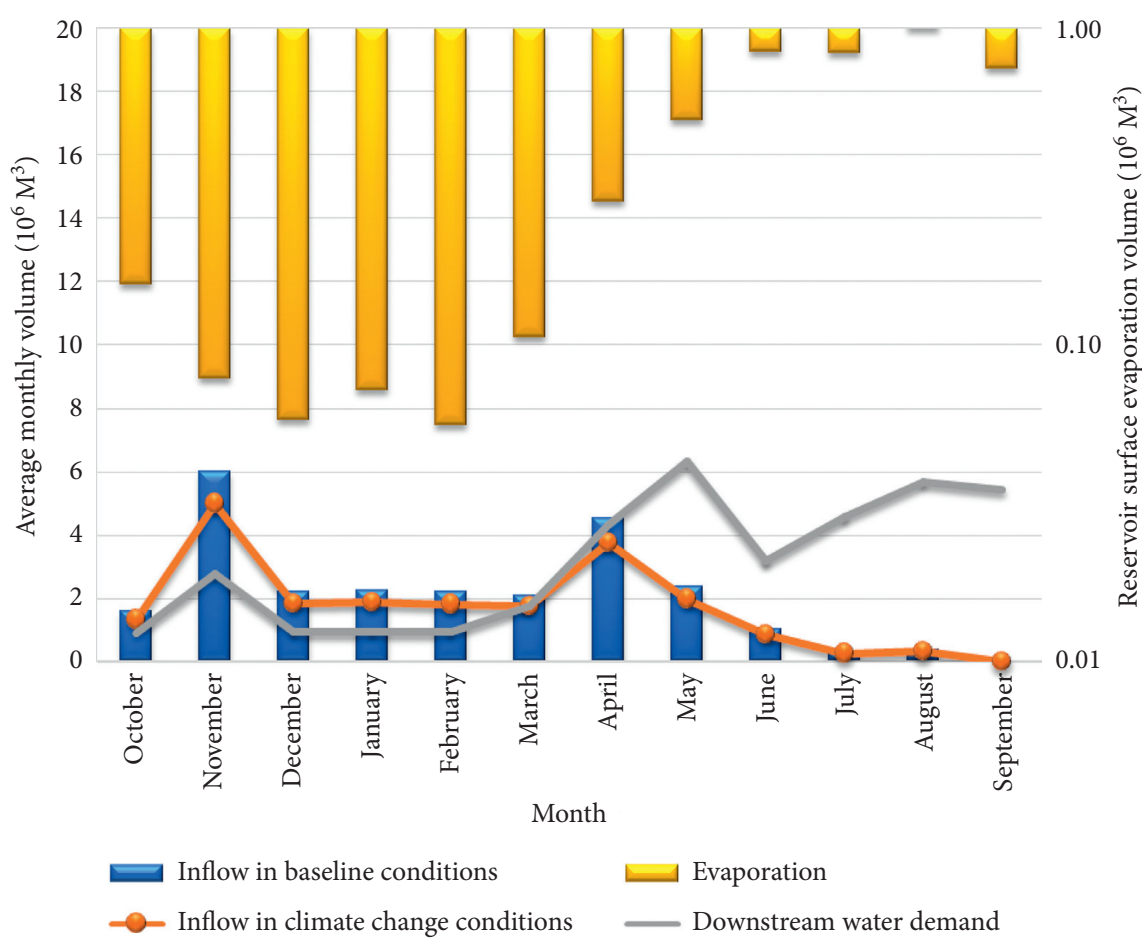

FIGURE 5: The average monthly release volume, as well as the monthly average evaporation volume and the monthly average demand volume, for water under baseline and climate change conditions.

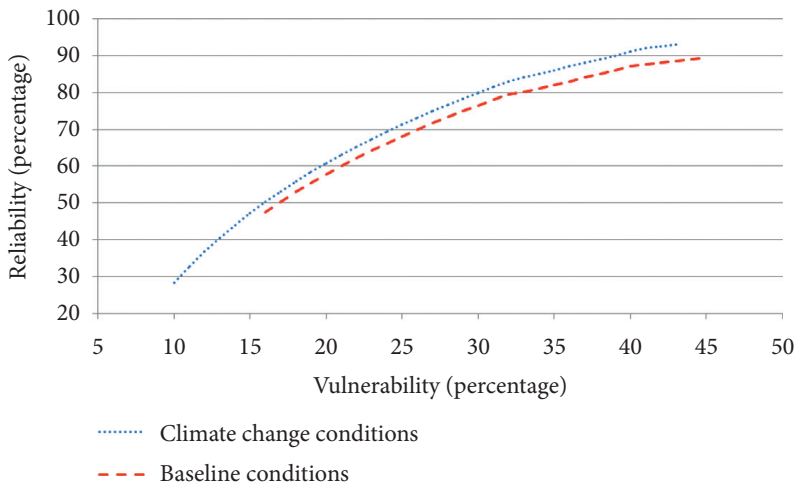

Figure 6: The comparison of the Pareto curve and changes in vulnerability and reliability objective functions.

Figure 6 shows that, in all the values of common reliability between baseline and climate change conditions (i.e., $45 \%$ to $89 \%$ ), the vulnerability values of the model have been significantly reduced, which will evaluate the model more stable in climate change conditions.

For the baseline and climate change conditions, the results for the supply of water demands for the 75 percent reliability index are stated in the Figures 7(a) and 8(a).

Compared to the corresponding demand for water, the following two alternatives were determined by the changes for shortages due to the optimal operational rules arising from the proposed optimization algorithm, as shown earlier. A comparison of the baseline and climate change conditions shows that, in the climate change conditions, the volume of released water from the reservoir is more consistent with irrigation demand. In addition, reservoir storage in the climate change conditions is lower compared with the baseline one, which is due to increases in the release (Figure 8(b)). The results are seen, respectively, in (Figure 7(b)) and (Figure 8(b)). Climate change release rates are higher than under baseline conditions, according to (Figure $7(\mathrm{a})$ ) and (Figure $8(\mathrm{a})$ ), which will be 10 percent due to the increased demand for water under climate change conditions.

On the other hand, Figures 7(b) and 8(b) indicate that, under climate change conditions, the output of the dam has also improved. In the next step, the objective function values of 75 percent reliability per Pareto point were calculated in 


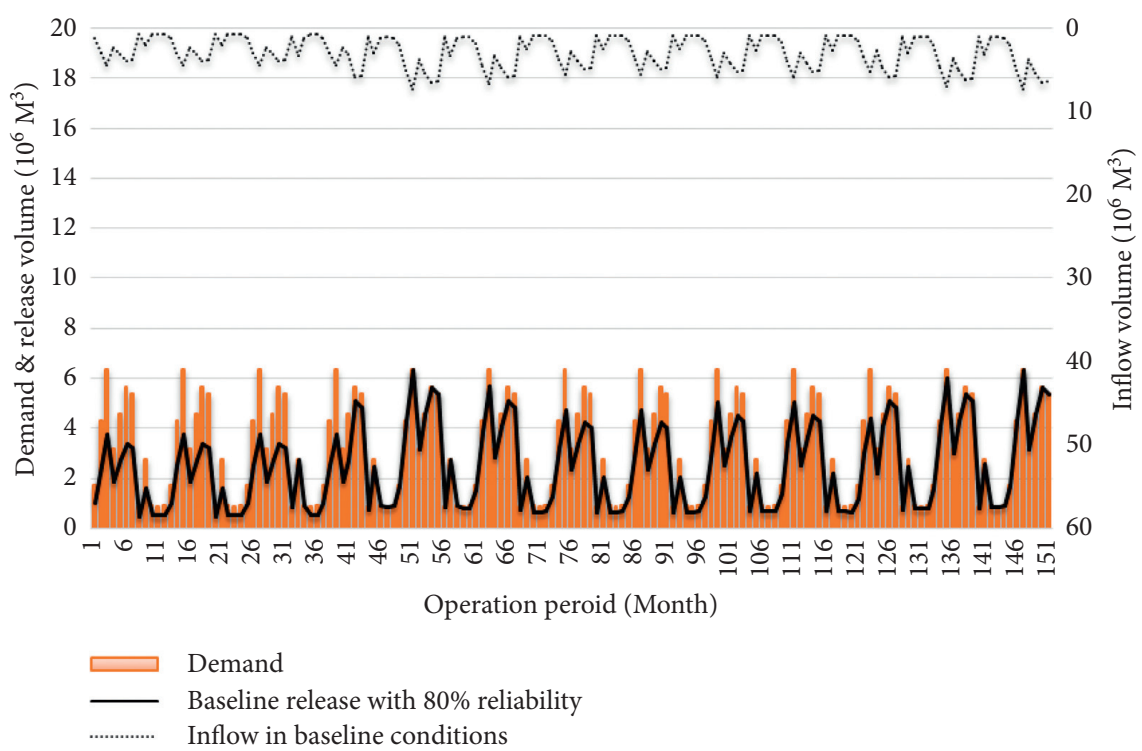

(a)

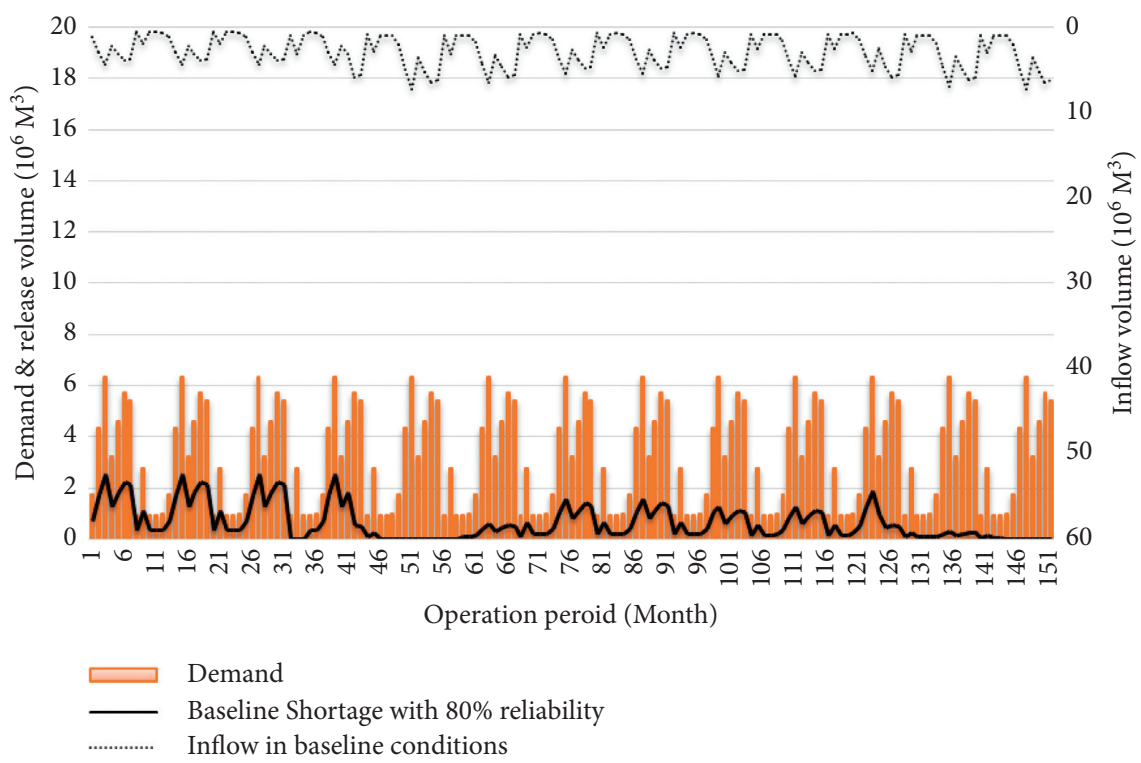

(b)

Figure 7: The comparison of (a) release volume (b) and shortage volume per each Pareto point resulted from 75\% reliability in baseline conditions.

the conditions to evaluate the reservoir output in the supply of downstream water requirements, as described in (Table 1). Reservoir release is more compatible with climate change conditions, according to (Table 1). Therefore, under the effects of climate change, the dam's performance is even better.
It should be mentioned that the results obtained in this study are consistent with the results obtained by other researchers such as Ashofteh et al. [12] and Donyaii et al. [4] who applied genetic programming and Farmland Fertility optimization algorithm, respectively. 


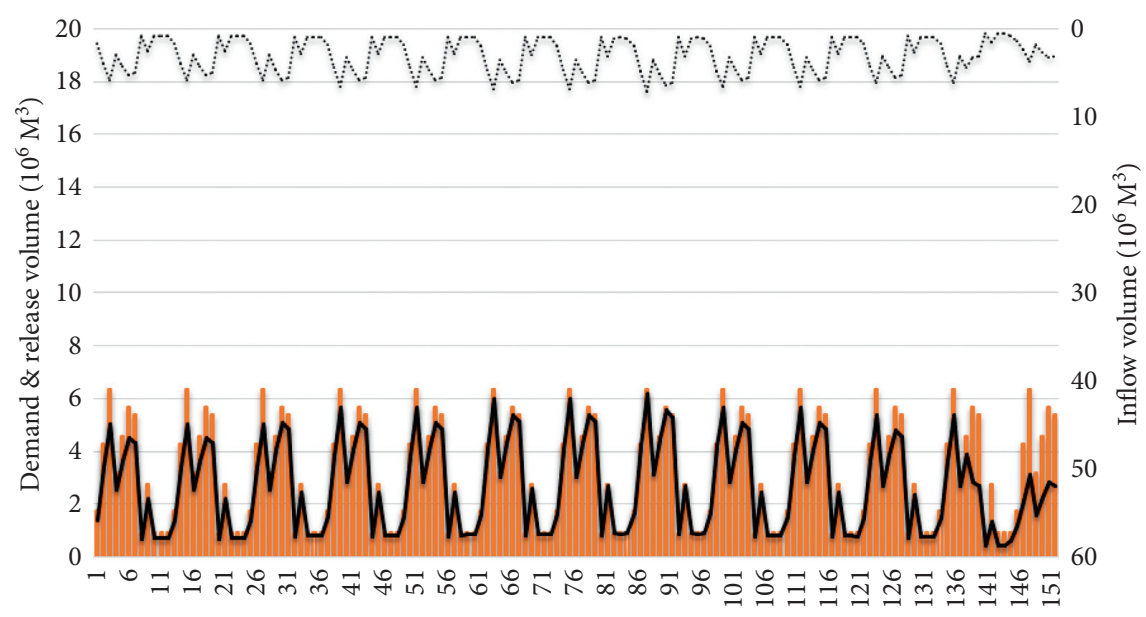

Operation peroid (Month)

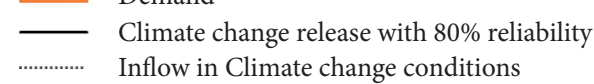

(a)

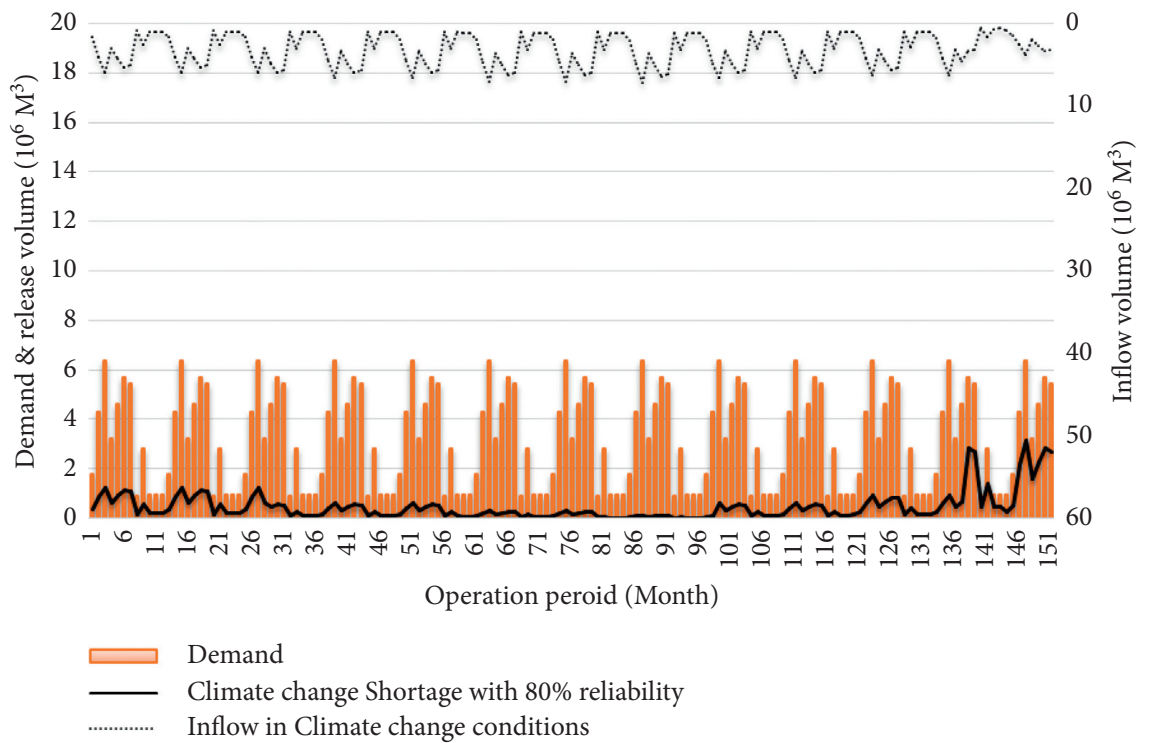

(b)

FIGURE 8: The comparison of (a) release volume and (b) shortage volume per each Pareto point resulted from 75\% reliability in climate change conditions.

TABle 1: The comparison of objective functions in baseline and climate change conditions for each Pareto point (75\% reliability).

\begin{tabular}{lcc}
\hline Conditions & Reliability (\%) & Vulnerability (\%) \\
\hline Baseline & 75 & 29 \\
Climate change & 75 & 27 \\
\hline
\end{tabular}

\section{Conclusions}

One of the main considerations in water resources management is to take into account all priorities within policies governing the development of water resources systems to satisfy water demand. Moreover, in the light of climate change, it is important to include a range of decisionmaking alternatives (Pareto curve) in such a manner that executive managers and operators can assess the relative value of the objectives in this respect. Therefore, it is unavoidable to derive multiobjective operating rules from reservoirs, as each of the curve points in the Pareto curve 
means a reservoir operation rule that can be modified under the conditions and policies regulating the catchment. The objective of this work was to draw up a general guideline for the operation of such Pareto points so that it could determine how to achieve these points such that 75 percent of the downstream Golestan Dam lands in Iran are provided with water needs.

In the current research, after assessing the climate change parameters such as temperature and precipitation values for baseline condition, they were predicted for the future period as the parameters of climate change conditions by downscaling the CANESM2 climate model with SDSM 4.2 software. Analyzing the average monthly precipitation variations have shown that the drop in the precipitation rate in the next period was obvious, and this trend has been diminished by to 21.1 percent regarding to the baseline as a warning for water resources management. Next, a secondorder Neurofuzzy model with a Gaussian membership function was conducted to simulate the rainfall-runoff process focusing on the climate change phenomena at the entrance to the Golestan Dam. Results showed that the volume of runoff during the climate change conditions with respect to the baseline period would be decreased to 0.17 percent. Finally, the Grey Wolf Optimization algorithm was used to solve the problem of the reservoir system of the Golestan Dam under baseline and climate change conditions in the province of Golestan. In order to obtain reservoir discharge rules (based on the Pareto curve), objective functions, including maximizing the reliability index and minimizing the vulnerability index, were based on parameters such as the discharge volume to the reservoir, the storage volume, and the water demand volume derived from the MOGWO algorithm. The study showed that the amount of vulnerability changes under the baseline and climate change conditions was 16 percent to 45 percent and 10 percent to 43 percent, respectively. Moreover, the reliability increase under the baseline and climate change conditions ranged from 47 percent to 90 percent and 27 percent to 93 percent, respectively. Meanwhile, for $75 \%$ reliability index of the model, the vulnerability ranged between $29 \%$ and $27 \%$ under the baseline and climate change conditions, respectively. In the next step, in order to evaluate the efficiency of the reservoir in meeting the downstream water requirements, in the abovementioned conditions, the values of the objective function were compared to 75 percent reliability. The results show that the rate of release of the reservoir is far more in line with the demand for climate change, so evidence is given that the Golestan Dam performs better under the conditions of climate change.

\section{Abbreviations}

$$
\begin{aligned}
& A_{(t)}: \\
& E v_{(t)}: \\
& a, b, c, d:
\end{aligned}
$$

\begin{tabular}{|c|c|}
\hline$Q_{(t)}:$ & $\begin{array}{l}\text { The inflow to the } \\
\text { reservoir in the } t \text {-th } \\
\text { month }\end{array}$ \\
\hline $\operatorname{Re}_{(t)}$ : & $\begin{array}{l}\text { The release from the } \\
\text { reservoir in the } t \text {-th } \\
\text { month }\end{array}$ \\
\hline$S p_{(t)}:$ & $\begin{array}{l}\text { The reservoir overflow } \\
\text { in the } t \text {-th month }\end{array}$ \\
\hline $\operatorname{Loss}_{(t)}:$ & The evaporation losses \\
\hline$S_{\max }$ and $S_{\min }:$ & $\begin{array}{l}\text { in the } t \text {-th month } \\
\text { Maximum and } \\
\text { minimum volumes of } \\
\text { the reservoir }\end{array}$ \\
\hline $\mathrm{Re}_{\max }$ and $\mathrm{Re}_{\min }$ : & $\begin{array}{l}\text { Maximum and } \\
\text { minimum releasable } \\
\text { volumes from the } \\
\text { reservoir }\end{array}$ \\
\hline$F_{1}:$ & $\begin{array}{l}\text { Objective function of a } \\
\text { vulnerability index }\end{array}$ \\
\hline$F_{2}:$ & $\begin{array}{l}\text { Objective function of } \\
\text { reliability index }\end{array}$ \\
\hline$D_{t}:$ & $\begin{array}{l}\text { Demand volume } \\
\text { throughout the } t \text {-th } \\
\text { period }\end{array}$ \\
\hline$D_{\mathrm{Max}}:$ & $\begin{array}{l}\text { Maximum water } \\
\text { demand in the operating } \\
\text { period }\end{array}$ \\
\hline$N_{t=1}^{T}\left(\operatorname{Re}_{t}<D_{t}\right)$ & $\begin{array}{l}\text { Number of months of } \\
\text { water shortage }\end{array}$ \\
\hline$N_{t=1}^{T}\left(D_{t}-\operatorname{Re}_{t} \mid \operatorname{Re}_{t} \geq D_{t}\right)$ & $\begin{array}{l}\text { Number of months of } \\
\text { water supply }\end{array}$ \\
\hline$\left[A^{\prime} \cdot\left(S_{\min }-S_{t} / S_{\max }-S_{\min }\right)+B^{\prime}\right]:$ & $\begin{array}{l}\text { Penalty function } \\
\text { achieved from the } \\
\text { violation of equation (9) }\end{array}$ \\
\hline$\left[C^{\prime} .\left(\operatorname{Re}_{t} / D_{\mathrm{Max}}\right)+D^{\prime}\right]:$ & $\begin{array}{l}\text { Penalty function } \\
\text { resulted from the } \\
\text { violation of equation } \\
\text { (10) }\end{array}$ \\
\hline$A^{\prime}$ to $D^{\prime}:$ & $\begin{array}{l}\text { Coefficients imply the } \\
\text { positive constants of } \\
\text { penalty functions with } \\
A^{\prime}=1, B^{\prime}=0.5, C^{\prime}=1, \\
\text { and } D^{\prime}=16 \text { values }\end{array}$ \\
\hline$g_{1}\left(Q_{b t}+S_{b t}+D_{b t}\right):$ & $\begin{array}{l}\text { The rule from MOGWO } \\
\text { in the baseline operating } \\
\text { period for baseline } \\
\text { conditions }\end{array}$ \\
\hline$g_{2}\left(Q_{\mathrm{ft}}+S_{\mathrm{ft}}+D_{\mathrm{ft}}\right):$ & $\begin{array}{l}\text { The rule from MOGWO } \\
\text { in the climate change } \\
\text { operating period for } \\
\text { climate change } \\
\text { conditions }\end{array}$ \\
\hline The $b$ index: & $\begin{array}{l}\text { For baseline conditions, } \\
f \text { index = for climate } \\
\text { change conditions }\end{array}$ \\
\hline GWO: & $\begin{array}{l}\text { Grey Wolf Optimization } \\
\text { Algorithm }\end{array}$ \\
\hline$X p:$ & Victim's location vector \\
\hline$X:$ & Grey wolf's position \\
\hline
\end{tabular}

Reservoir surface in the The $b$ index: $t$-th month

Net evaporation from

the reservoir

Constant coefficients of the surface-volume equation
$X$ : 


$\begin{array}{ll}\text { C: } & \text { Coefficient's vector } \\ D: & \text { Direction between the } \\ & \text { wolf and the prey } \\ \left(X_{(t)}\right): & \text { Prey position } \\ \vec{r}_{1} \text { and } \vec{r}_{2}: & \text { Randomly selected value } \\ & \text { of }[0,1] \\ \vec{a}: & \text { Fixed quantity of } \\ & \text { iterations reduced from } \\ & 2 \text { to } 0 \\ A: & \text { Proposed values given } \\ & \text { in }[-2,2] \\ R^{2}: & \text { Correlation coefficient. }\end{array}$

\section{Data Availability}

The manuscript data can be obtained from the Shock and Vibration Journal.

\section{Conflicts of Interest}

The authors declare that they have no conflicts of interest.

\section{References}

[1] M. A. Hariri-Ardebili, S. Mahdi Seyed-Kolbadi, V. E. Salamon, J. W. Salamon, and L. K. Nuss, "Anatomy of the vibration characteristics in old arch dams by random field theory," Engineering Structures, vol. 179, no. 15, pp. 460-475, 2019.

[2] H. Mirzabozorg, M. A. Hariri-Ardebili, M. Heshmati, and S. M. Seyed-Kolbadi, "Structural safety evaluation of Karun III Dam and calibration of its finite element model using instrumentation and site observation," Case Studies in Structural Engineering, vol. 1, pp. 6-12, 2014.

[3] M. A. Hariri-Ardebili, H. Rahmani-Samani, and M. Mirtaheri, "Seismic stability assessment of a high-rise concrete tower utilizing endurance time analysis," International Journal of Structural Stability and Dynamics, vol. 14, no. 6, Article ID 1450016, 2014.

[4] A. R. Donyaii, A. P. Sarraf, and H. Ahmadi, "Application of a new approach in optimizing the operation of the multi-objective reservoir," Journal of Hydraulic Structures, vol. 6, no. 3, pp. 1-22, 2020.

[5] X. Sun, J. Luo, and J. Xie, "Multi-objective optimization for reservoir operation considering water diversion and power generation objectives," Water, vol. 10, no. 11, p. 1540, 2018.

[6] A. R. Donyaii, A. P. Sarraf, and H. Ahmadi, "Presenting a new hybrid evolutionary algorithm in optimizing reservoir operation based on new combinative distance-based assessment techniques (CODAS)," Journal of Water and Soil Conservation, in Persian, 2020.

[7] X. Wu, X. Wei, and W. Guo, "Multi-objective ecological operation model of cascade hydropower reservoirs," in Proceedings of the International Workshop on Information and Electronics Engineering (IWIEE), pp. 3996-4001, Harbin, China, March 2012.

[8] P. S. Ashofteh, O. Bozorg Haddad, H. Akbari-Alashti, and M. A. Mariño, "Determination of irrigation allocation policy under climate change by genetic programming," Journal of Hydrologic Engineering, vol. 141, no. 4, Article ID 04014059, 2014.

[9] M. Ehteram, H. Karami, S. F. Mousavi, S. Farzin, A. B. Celeste, and A.-E. Shafie, "Reservoir operation by a new evolutionary algorithm: Kidney algorithm," Water Resources Management, vol. 32, no. 14, pp. 4681-4706, 2018.

[10] S. Afkhamifar and A. P. Sarraf, "Prediction of groundwater level in Urmia plain aquifer using hybrid model of wavelet transform-extreme learning machine based on quantum particle swarm optimization," Watershed Engineering and Management, vol. 12, no. 2, pp. 351-364, 2020, in Persian.

[11] M. Nouri, "Management of multi-objective and multi-reservoir water resources systems using optimization models in climate change conditions," Ph.D. thesis, Faculty of Civil Engineering, Ferdowsi University of Mashhad, Mashhad, Iran, 2015.

[12] P. S. Ashofteh and O. Bozorg Haddad, "Using GP optimization tools developed for the multi-objective operation of reservoirs in climate change," Iranian Journal of Soil and Water Research, vol. 46, no. 3, pp. 415-422, 2015.

[13] S. Mirjalili, S. M. Mirjalili, and A. Lewis, "Grey wolf optimizer," Advances in Engineering Software, vol. 69, pp. 46-61, 2014.

[14] R. Karami Mohammadi, M. Mirjalaly, M. Mirtaheri, and M. Nazeryan, "Comparison between uniform deformation method and genetic algorithm for optimizing mechanical properties of dampers," Earthquakes and Structures, vol. 1, no. 14, pp. 1-10, 2018.

[15] M. Mirtaheri, S. Sehat, and M. Nazeryan, "Improving the behavior of buckling restrained braces through obtaining optimum steel core length," Structural Engineering and Mechanics, vol. 65, no. 4, pp. 401-408, 2018. 